\title{
An interesting approach for Biofilm disruption by Thermocouple device
}

\author{
Krithika Parthiban ${ }^{1 *}$, Pragya Tamarakar ${ }^{1 *}$, Mahua Ghosh ${ }^{2}$, Priya Gopal ${ }^{3}$, Prosun Tribedi ${ }^{4}$, Bannhi Das ${ }^{1 \#}$ \\ Department of Biotechnology, Mount Carmel College, Autonomous, Bengaluru, 560001, India \\ Department of Physics, Mount Carmel College, Autonomous, Bengaluru, 560001, India \\ Department of Microbiology, Muralidhar Girls College, West Bengal- 700029, India \\ Department of Biotechnology, Microbial Ecology Laboratory, The Neotia University, West Bengal-743368, India \\ Corresponding author (\#)Dr. Bannhi Das - bannhi.das@gmail.com
}

\begin{abstract}
Microbial biofilm are an aggregate of microbial population encompassed in a matrix of self secreted extracellular polymeric substances (EPS). In various sectors from human health to industries biofilm bring with it an array of harmful impacts. For instance, biofilm linked diseases like chronic otitis, chronic osteomyelitis, urinary tract infections, cystic fibrosis-associated lung infection etc. cannot be treated with regular antibiotics since profound use of the same have led to the existence of several drug resistant strains. Effective techniques for combating this bacterial biofilm are still a challenging issue to the scientific community. Towards this direction, in the present study efforts have been put to use electric shock generated by a thermocouple device to disrupt bacterial biofilm formation. The uniqueness of the procedure lies with the method of generation of the electric shock, wherein a difference in temperature has been exploited to create the shock. Using this method, electric shocks of $105 \mu \mathrm{V}$ was applied for different durations on bacterial biofilm formed by Pseudomonas sp. and Staphylococcus sp. In each case a difference in response was observed which led to the conclusion that Staphylococcal biofilm as well as Pseudomonal biofilm are susceptible to the electric shocks. Hence, this interesting method of usage of low voltage electric shock could be a potential method to fight against biofilm threats.
\end{abstract}

Keywords: Bacterial biofilm, thermocouple device, low voltage electric shock, Pseudomonas sp., Staphylococcus sp.

\section{Introduction}

In nature microorganisms can live in either free-living form or as biofilm (Chakraborty et al. 2020). Biofilm is defined as an organized array of homogenous or heterogeneous cluster of microorganisms embedded on a self-secreted matrix made of extracellular polymeric substances (EPS) (Cortes et al. 2011). In many cases, microbial biofilm have executed antibiotic resistance property and an ease to escape host immune responses (Gupta et al. 2016). In a report published by National Institutes of Health $(\mathrm{NIH})$ it was mentioned that $80 \%$ of the microbial infections were biofilm linked in human hosts which included urinary tract infections, catheter infections, formation of dental plaques and cystic fibrosis (Yakandawala et al 2006; Cortes et al. 2011). Moreover, in various industrial sectors, biofilm formation in fluid carrying pipelines have resulted in disrupting the efficiency of the machines by hampering the heat transfer as well as reducing the rate of liquid flow in the storage tanks such as fermenters or in heat exchangers (Patel et al. 2014; Chan et al. 2019). In this context, Gupta et al. (2016) stated multiple microorganisms like Pseudomonas fluorescens, Pseudomonas aeruginosa, Escherichia coli, Staphylococcus aureus, Staphylococcus equi etc. to be potent biofilm forming organisms (Gupta et al. 2016). Hence, in this study, Staphylococcus sp. as well as Pseudomonas sp. have been selected as test organisms. Staphylococcus sp. is a round shaped, grampositive bacteria which colonize on any site of the human body leading to development of chronic diseases including osteomyelitis, medical device implants, endocarditis, and persistence in the cystic fibrosis lung (Yarwood and Schlievert 2003; Paharik and Horswill 2016). On the other hand, Pseudomonas sp. is a gram-negative, rod shaped bacteria which is accountable for multiple acute diseases like urinary tract, kidney infections, bacteraemia etc. (Sharma et al. 2014; Gupta et al. 2016). In each case, a drug resistance property is noticed where the antibiotics get hindered in the EPS layer, thereby, failing to penetrate through the biofilm structure and reach the target sight (Stewart and Costerton 2001). Hence, scientists all over the world are coming up with new techniques like phage therapy (Khalifa et al. 2015)in some cases, than conventional antibiotics, especially regarding multidrug-resistant biofilm infections. The objective here was to isolate an anti- Enterococcus faecalis bacteriophage and to evaluate its efficacy against planktonic and biofilm cultures. $\mathrm{E}$. faecalis is an important pathogen found in many infections, including endocarditis and persistent infections associated with root canal treatment failure. The difficulty in $\mathrm{E}$. faecalis treatment has been attributed to the lack of anti-infective strategies to eradicate its biofilm and to the frequent emergence of multidrug-resistant strains. To this end, an anti- E. faecalis and E. faecium phage, termed EFDG1, was isolated from sewage effluents. The phage was visualized by electron microscopy. EFDG1 coding sequences and phylogeny were determined by whole genome sequencing (GenBank accession number KP339049, use of silver nanoparticles (Siddique et al. 2020), antimicrobial peptides (de la Fuente-Núñez and Hancock 2015), polysaccharides (Valle et al. 2006), chelating-agents (Abraham et al. 2012), enzymes (Saggu et al. 2019) and combinatorial approaches (Das et al. 2016; Tagliaferri et al. 2019) to attenuate microbial biofilm. In this context, a novel strategy was introduced by Kim et al. (2015) which claimed an increase in antibiotic potential when these are used in combination with alternating (AC), direct (DC) or superimpose (SP) potential (Kim et al. 2015). Moreover, another report stated that application of $2000 \mu \mathrm{A}$ of current can reduce the biofilm formation by Staphylococcus epidermis (Ruiz-Ruigomez et al. 2016). Thus, in this study we have focused on using low voltage electric shock produced by a thermocouple device for potential disruption of biofilm. A thermocouple device consists of bi- metal junctions maintained at different temperatures which develop a thermo-emf and provides enough practical applications. Efforts have been put to examine the inhibitory effect of low voltage electric shock $(105 \mu \mathrm{V})$ on Pseudomonal 
and Staphylococcal biofilm formed under laboratory conditions. The use of an open circuit to generate an electric shock for disruption of bacterial biofilm may provide a novel, in-expensive and flexible approach towards the control of threats caused by microbial biofilm.

\section{MATERIALS AND METHODS}

\section{Estimation of formed bacterial biofilm by crystal violet assay}

To study the bacterial biofilm formation the strains of Pseudomonas sp and Staphylococcus sp were isolated from the soil. Characterisations of the strains were performed according to Holt et al. 1994 and Dong and Cai, 2001. For examining the biofilm forming potential of the tested organisms, $100 \mu$ of overnight culture was inoculated in $5 \mathrm{ml}$ of fresh media and incubated in Petri plates (4.5 $\mathrm{cm}$ diameter) and incubated for $24 \mathrm{~h}, 48 \mathrm{~h}$ and 72 . Post incubation the formed biofilm was estimated by conducting the crystal violet assay (CV assay) as mentioned in Tribedi and Sil 2014.

\section{Thermocouple device}

A thermocouple device consists of two dissimilar electrical conductors forming a bi-metallic junction which can produce electric voltage. The thermo emf generated by it can be estimated by using Spot Galvanometer that shows deflections proportional to the potential difference generated. In our experimental setup the sensitivity of the instrument was $8 \mu \mathrm{v} /$ division. A thermocouple made of iron-copper for generation of electric shock was used for our experiment. Temperature difference was maintained by using distilled water at room temperature and ice. This experimental setup is depicted in Figure 1.
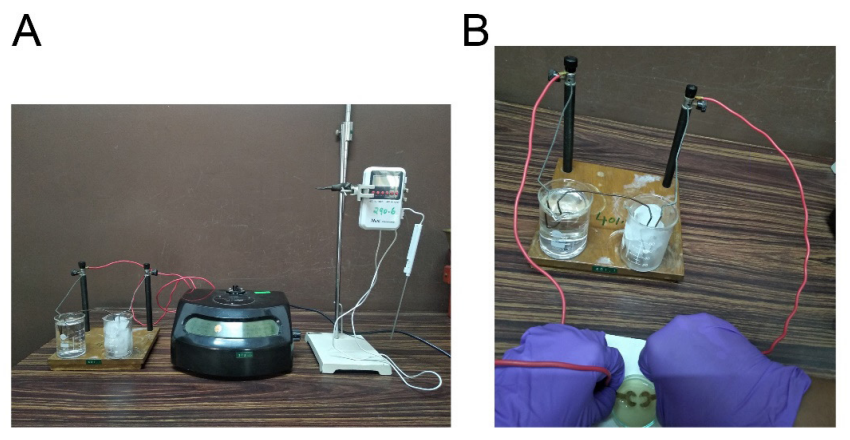

Fig 1. Thermocouple device. A. Thermocouple device connected with spot galvanometer. B. Experimental setup for electric shock application

\section{Application of low voltage electric shock on bacterial biofilm formation}

The culture plates were inoculated and incubated for $24 \mathrm{~h}$, $48 \mathrm{~h}$ and $72 \mathrm{~h}$ to check the biofilm formation by the tested organisms, Pseudomonas sp. and Staphylococcus sp. Thereafter, the established bacterial biofilm was treated with a low voltage electric shock $(105 \mu \mathrm{V})$ for 10 min using a thermocouple device. A temperature difference of $25^{\circ} \mathrm{C}$ was maintained by using ice and distilled water kept at room temperature to generate the necessary low voltage electric shock. The electrodes were held at a distance of $0.5 \mathrm{~cm}$ inside the Petri plates with its ends touching the bottom surface where biofilm formation occurs. The plates were subjected to electric shock at three different time frames, at an interval of $24 \mathrm{~h}$ for 3 days. Throughout the experiment untreated plates were used as control. Finally, CV assay was performed to calculate the amount of biofilm present after $24 \mathrm{~h}$ time interval of each treatment with electric shock.

Application of an increased duration of electric shock on bacterial biofilm formation

The bacterial culture was inoculated and the biofilm formation was allowed till $72 \mathrm{~h}$. After every $24 \mathrm{~h}$ for the 3 days of incubation the established bacterial biofilm was treated with low voltage electric shock $(105 \mu \mathrm{V})$ using a thermocouple device. This shock was generated by maintaining a temperature difference of $25^{\circ} \mathrm{C}$ using ice and distilled water kept at room temperature and applied for $15 \mathrm{~min}$. The electrodes were held at a distance of $0.5 \mathrm{~cm}$ inside the Petri plate. Untreated plates were used as control and CV assay was performed after $24 \mathrm{~h}$ of electric shock application. Absorbance was recorded at $580 \mathrm{~nm}$ after performing the CV assay. The same method was followed for both Pseudomonas sp and Staphylococcus sp simultaneously.

\section{Result and Discussion}

\section{Estimation of biofilm formation by crystal violet assay}

To determine the biofilm formation efficiency of the tested Pseudomonas sp. and Staphylococcus sp. the crystal violet assay was performed. The assay has been quite frequently employed in multiple literature to examine the extent of microbial biofilm development (Mukherjee et al. 2013; Sharma et al. 2015). The result of the CV assay performed at an interval of $24 \mathrm{~h}$ for 3 days showed a successful biofilm formation by the tested organisms (Table 1). The data indicates that with time the amount of formed biofilm increased. In this context, Staphylococcus sp. was found to execute a better biofilm forming potential at $72 \mathrm{~h}$ in comparison to Pseudomonas $s p$ at identical laboratory conditions (Table 1, Fig 2).

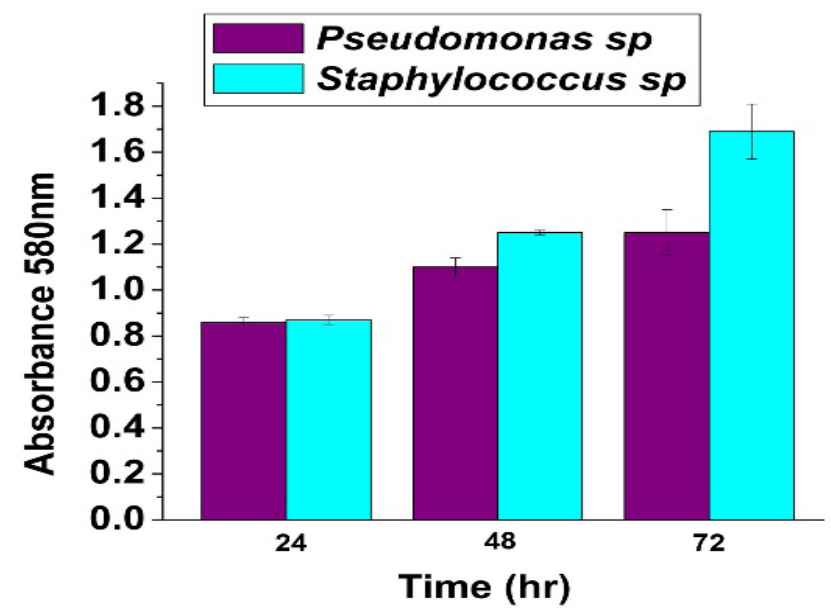

Fig 2. Standardisation of Biofilm formation by Pseudomonas sp and Staphylococcus sp. CV assay was performed after $24 \mathrm{hr}, 48 \mathrm{hr}$ and $72 \mathrm{hr}$ of inoculation, for biofilm estimation of both Pseudomonas sp. and Staphylococcus sp. Absorbance measured at 580nm.

Table 1. Crystal violet assay for biofilm estimation

\begin{tabular}{|l|l|l|l|l|}
\hline Time (h) & \multicolumn{2}{|l|}{ Pseudomonas sp } & \multicolumn{2}{l|}{ Staphylococcus sp } \\
\hline & OD 580nm & SD & OD 580nm & SD \\
\hline
\end{tabular}




\begin{tabular}{|l|l|l|l|l|}
\hline 24 & 0.86 & 0.02 & 0.875 & 0.02 \\
\hline 48 & $1.10^{*}$ & 0.04 & $1.12^{*}$ & 0.02 \\
\hline 72 & $1.25^{*}$ & 0.10 & $1.69^{*}$ & 0.12 \\
\hline
\end{tabular}

${ }^{*}$ Absorbance was measured with 10 \& 20 fold dilution.

\section{Effect of low voltage electric shock on bacterial biofilm formation}

Biofilm formation in Pseudomonas sp was found to decrease when treated with an electric shock of $105 \mu \mathrm{V}$ generated by the thermocouple device. However, a more prominent decrease in the amount of biofilm present was noticed when the shock was given to the culture after $48 \mathrm{~h}$ and $72 \mathrm{~h}$ of incubation (Table 2A \& Fig 3A).

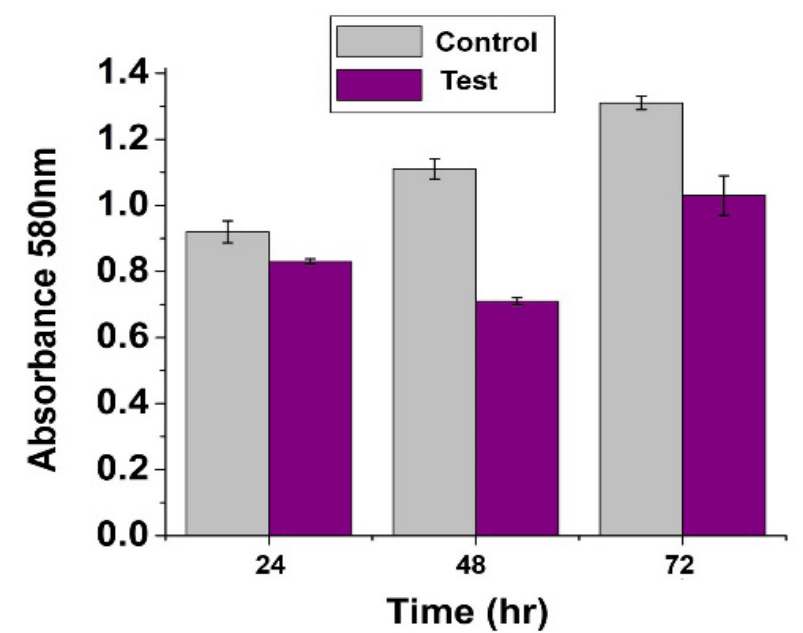

Fig 3A. Effect of $105 \mu \mathrm{V}$ of electric shock for 10 mins on Pseudomonas $s p$ Biofilm. Bacterial culture was allowed to form biofilm for 24,48 and $72 \mathrm{hrs}$ and subjected to $105 \mu \mathrm{V}$ of electric shock for $10 \mathrm{mins}$ at $24 \mathrm{hr}$, $48 \mathrm{hr}$ and $72 \mathrm{hr}$. CV assay was performed after $24 \mathrm{hrs}$ of electric shock treatment for each of the culture.

Table 2A. Effect of low voltage electric shock, $105 \mu \mathrm{V}$ on Pseudomonas sp biofilm

\begin{tabular}{|c|c|c|c|}
\hline \multirow{2}{*}{$\begin{array}{l}\text { Time (in h) for } \\
\text { Electric Shock } \\
\text { (with respect } \\
\text { to inoculation } \\
\text { time) }\end{array}$} & \multirow{2}{*}{$\begin{array}{l}\text { Time (in h) for } \\
\text { CV assay(with } \\
\text { respect to } \\
\text { inoculation } \\
\text { time) }\end{array}$} & \multicolumn{2}{|c|}{ Pseudomonas sp } \\
\hline & & Control & Test \\
\hline $24 \mathrm{~h}$ & $48 \mathrm{~h}$ & 0.92 & 0.83 \\
\hline $48 \mathrm{~h}$ & $72 \mathrm{~h}$ & $1.11^{*}$ & 0.71 \\
\hline $72 \mathrm{~h}$ & $96 \mathrm{~h}$ & $1.31^{*}$ & $1.03^{*}$ \\
\hline
\end{tabular}

${ }^{\star}$ Absorbance was measured with 10 -fold dilution.

The Staphylococcus sp too showed sensitivity towards the electric shock (table 2B \& Fig 3B). However, the data indicates that the Staphylococcus $s p$ is more sensitive towards the electric shock compared to the Pseudomonas sp. In both the bacteria the effect of the electric shock is better if it's given after $48 \mathrm{~h}$ of inoculation or biofilm formation. As the culture grows older, the biofilm formed tend to become more resistant towards the electric shock as depicted by the CV assay performed on the $72 \mathrm{~h}$ culture for both Pseudomonas and Staphylococcus.
Table 2B. Effect of low voltage electric shock on Staphylococcus sp biofilm

\begin{tabular}{|c|c|c|c|}
\hline \multirow{2}{*}{$\begin{array}{l}\text { Time (in hr) for } \\
\text { Electric Shock } \\
\text { (with respect to } \\
\text { inoculation time) }\end{array}$} & \multirow{2}{*}{$\begin{array}{c}\text { Time (in hr) } \\
\text { for CV assay } \\
\text { (with respect to } \\
\text { inoculation time) }\end{array}$} & \multicolumn{2}{|c|}{ Staphylococcus sp } \\
\hline & & Control & Test \\
\hline $24 \mathrm{~h}$ & $48 \mathrm{~h}$ & 0.91 & 0.89 \\
\hline $48 \mathrm{~h}$ & $72 \mathrm{~h}$ & $1.19^{*}$ & 0.64 \\
\hline $72 \mathrm{~h}$ & $96 \mathrm{~h}$ & $1.58^{*}$ & $1.04^{*}$ \\
\hline
\end{tabular}

${ }^{*}$ Absorbance was measured with 10 -fold dilution.

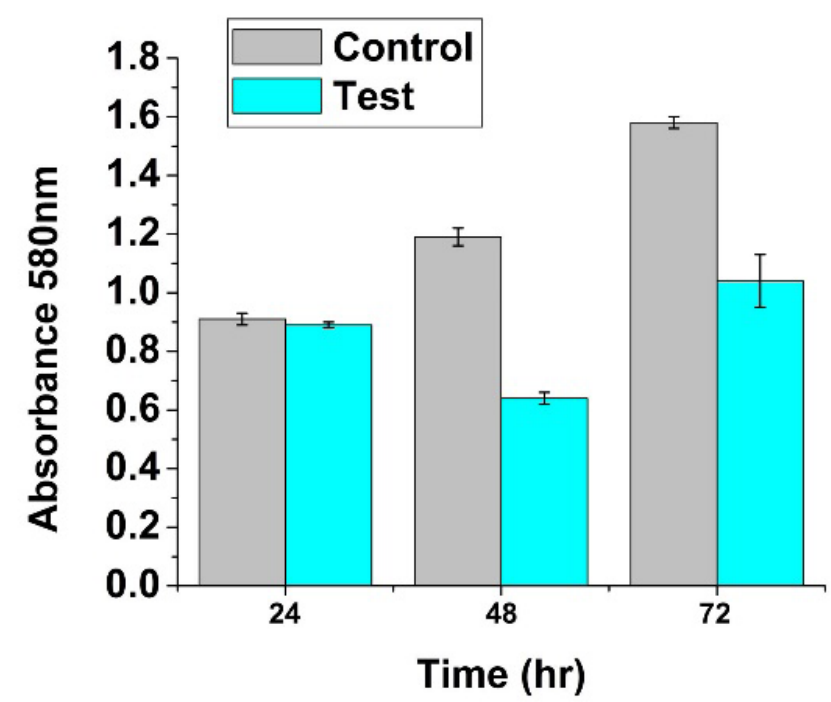

Fig 3B. Effect of $105 \mu \mathrm{V}$ electric shock for 10 mins on Staphylococcus biofilm. Bacterial culture was allowed to form biofilm for 24, 48 and $72 \mathrm{hrs}$ and subjected to $105 \mu \mathrm{V}$ of electric shock for $10 \mathrm{mins}$ at $24 \mathrm{hr}$, $48 \mathrm{hr}$ and $72 \mathrm{hr}$. CV assay was performed after $24 \mathrm{hrs}$ of electric shock treatment for each of the culture.

Effect of increased duration of electric shock on bacterial biofilm formation

Considering an effect of low voltage electric shock $(105 \mu \mathrm{V}$ for $10 \mathrm{~min}$ ) on disruption of bacterial biofilm, attempts were made to investigate the effect of increased duration of the same strength of electric shock on the bacterial biofilm formation. On increasing the duration of $105 \mu \mathrm{V}$ electric shock to $15 \mathrm{~min}$, to a $72 \mathrm{~h}$ old biofilm, a significant decrease in the absorbance in the CV assay was observed for both Pseudomonas and Staphylococcus (Table 3 and Fig 4). This decrease in absorbance confirmed a successful effect of increased duration of the electric shock on the $72 \mathrm{~h}$ old bacterial biofilm. This data also indicates that to disrupt the biofilm developed over higher time frames an increased duration of the shock is also required.

Table 3. Effect of low voltage electric shock for $15 \mathrm{mins}$ on Pseudomonas sp and Staphylococcus sp biofilm

\begin{tabular}{|l|l|l|}
\hline Organism & Control & Test \\
\hline Pseudomonas sp & $1.32^{*}$ & 0.78 \\
\hline Staphylococcus sp & $1.55^{\star}$ & 0.82 \\
\hline
\end{tabular}

${ }^{*}$ Absorbance was measured with 10 -fold dilution. 


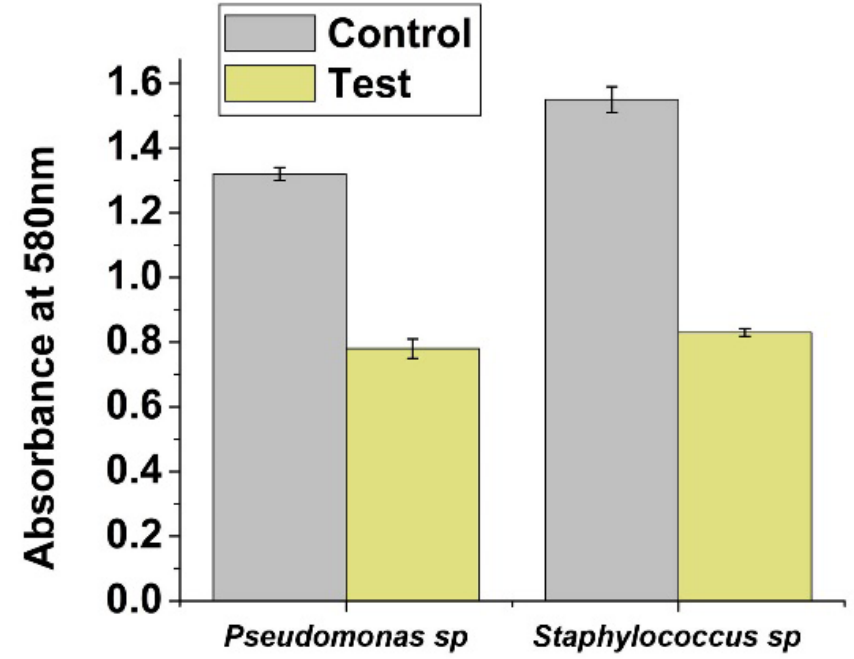

Fig 4. Effect of $105 \mu \mathrm{V}$ electric shock for 15 mins on Pseudomonas and Staphylococcus biofilm. Biofilm formation was carried for $72 \mathrm{hrs}$ and then the cultures were treated with $105 \mu \mathrm{V}$ of electric shock for $15 \mathrm{mins}$. CV assay was performed after $24 \mathrm{hrs}$ of the shock application.

\section{Conclusion}

The study indicates the possibility of using mild electric shock to disrupt bacterial biofilm formation. The advantage of this approach lies in the fact that the thermo-electric voltage can be varied by increasing or decreasing the temperature difference. Based on the observation it can be claimed that the duration for which the biofilms were subjected to electric shock plays an important role in the process of disruption. This signifies that the reduction in the amount of biofilm is proportional to time duration of exposure and the applied voltage. The data also indicates that biofilm from different organisms will show different extent of inhibition on treatment of the biofilms with electric shocks. However, creating a steady temperature difference for the generation of the wide ranges of electric shocks in the laboratory condition can be challenging; though it opens a new avenue for designing efficient instruments for the process. The exact mechanism of how biofilm is being disrupted by this method has not been the look out of this study but the concept can lead to the development of a device highly effective and widely applicable in biofilm disruption technologies.

\section{Acknowledgments}

The authors would like to thank Dr. Indranil Gupta, for his valuable contributions for the improvement of the manuscript.

\section{Conflict of interest}

The authors declare that they have no conflict of interest.

\section{Reference}

1. Abraham NM, Lamlertthon S, Fowler VG, Jefferson KK (2012) Chelating agents exert distinct effects on biofilm formation in Staphylococcus aureus depending on strain background: role for clumping factor B. J Med Microbiol 61 (Pt 8): 1062

2. Dong, X.Z. and Cai, M.-Y. (2001) Handbook of Common Bacteria Systematic Identify. Beijing: Science press.

3. Chakraborty P, Dastidar DG, Paul P, Dutta S, Basu D, Sharma
SR, Basu S, Sarker RK, Sen A, Sarkar A, Tribedi P (2020) Inhibition of biofilm formation of Pseudomonas aeruginosa by caffeine: a potential approach for sustainable management of biofilm. Arch. Microbiol 202 (3): 623-35

4. Chan S, Pullerits K, Keucken A, Persson KM, Paul CJ, Rådström $P(2019)$ Bacterial release from pipe biofilm in a full-scale drinking water distribution system. npj Biofilms and Microbiomes 5 (1): $1-8$

5. Cortes ME, Consuegra J, Sinisterra RD (2011) Bioflm formation, control and novel strategies for eradication. Sci Against Microbial Pathog Commun Curr Res Technol Adv 2:896-905

6. Das MC, Paul S, Gupta P, Tribedi P, Sarkar S, Manna D, Bhattacharjee S (2016) 3-Amino-4-aminoximido furazan derivatives: small molecules possessing antimicrobial and antibiofilm activity against Staphylococcus aureus and Pseudomonas aeruginosa. J Appl Microbiol 120:842-859

7. de la Fuente-Núñez C, Hancock RE (2015) Using anti-biofilm peptides to treat antibiotic-resistant bacterial infections. Postdoc journal: a journal of postdoctoral research and postdoctoral affairs 3 (2): 1

8. Gupta P, Sarkar S, Das B, Bhattacharjee S, Tribedi P (2016) Bioflm, pathogenesis and prevention-a journey to break the wall: a review. Arch Microbiol 198(1):1-15

9. Holt, J.G., Krieg, N.R., Sheath, P.H.A., Staley, J.T. and Williams, S.T. (1994) Bergey's Manual of Determinative Bacteriology (9th Edition). Baltimore, Maryland, USA: Williams \& Wilkins

10. Khalifa L, Brosh Y, Gelman D, Coppenhagen-Glazer S, Beyth S, Poradosu-Cohen R, Que YA, Beyth N, Hazan R (2015) Targeting Enterococcus faecalis biofilms with phage therapy. Appl Environ Microbiol 81 (8): 2696-2705

11. Kim YW, Subramanian S, Gerasopoulos K, Ben-Yoav H, Wu HC, Quan D, Carter K, Meyer MT, Bentley WE, Ghodssi R (2015) Effect of electrical energy on the efficacy of biofilm treatment using the bioelectric effect. npj Biofilms and Microbiomes 1 (1): 1-8

12. Mukherjee K, Tribedi P, Mukhopadhyay B, Sil AK (2013) Antibacterial activity of long-chain fatty alcohols against mycobacteria. FEMS Microbiol Lett 338(2):177-183

13. Paharik AE, Horswill AR (2016) The Staphylococcal Biofilm: Adhesins, regulation, and host response. Microbiol Spectr. 4(2):10.1128/microbiolspec. VMBF-0022-2015. doi:10.1128/ microbiolspec

14. Patel I, Patel V, Thakkar A, Kothari V (2014) Microbial biofilms: microbes in social mode. Int J Res Agric Food Sci 3 (2)

15. Ruiz-Ruigomez M, Badiola J, Schmidt-Malan SM, GreenwoodQuaintance K, Karau MJ, Brinkman CL, Mandrekar JN, Patel $\mathrm{R}$ (2016) Direct electrical current reduces bacterial and yeast biofilm formation. J Bacteriol 2016

16. Saggu SK, Jha G, Mishra PC (2019) Enzymatic degradation of biofilm by metalloprotease from Microbacterium sp. SKS10. Front Bioeng Biotechnol 7: 192 
17. Sharma G, Rao S, Bansal A, Dang S, Gupta S, Gabrani R (2014) Pseudomonas aeruginosa biofilm: potential therapeutic targets. Biologicals 42 (1): 1-7

18. Sharma BK, Saha A, Rahaman L, Bhattacharjee S, Tribedi P (2015) Silver inhibits the biofilm formation of Pseudomonas aeruginosa. Adv Microbiol 5(10): 677

19. Siddique MH, Aslam B, Imran M, Ashraf $A$, Nadeem $H$, Hayat S, Khurshid M, Afzal M, Malik IR, Shahzad M, Qureshi U (2020) Effect of Silver Nanoparticles on Biofilm Formation and EPS Production of Multidrug-Resistant Klebsiella pneumoniae. BioMed Research International 2020

20. Stewart PS, Costerton JW (2001) Antibiotic resistance of bacteria in biofilms. The lancet 358 (9276): 135-8

21. Tagliaferri TL, Jansen M, Horz HP (2019) Fighting pathogenic bacteria on two fronts: Phages and antibiotics as combined strategy. Front Cell Infect Microbiol 9: 22
22. Tribedi P, Sil AK (2014) Cell surface hydrophobicity: a key component in the degradation of polyethylene succinate by $\mathrm{P}$ seudomonas sp. AKS2. J Appl Microbiol 116 (2): 295-303

23. Valle J, Da Re S, Henry N, Fontaine T, Balestrino D, LatourLambert P, Ghigo JM (2006) Broad-spectrum biofilm inhibition by a secreted bacterial polysaccharide. Proc Natl Acad Sci 103 (33): 12558-12563

24. Yakandawala N, Gawande PV, Madhyastha LK (2006) Efect of ovotransferrin, protamine sulfate and EDTA combination on bioflm formation by catheter-associated bacteria. J Appl Microbiol 102:722-727

25. Yarwood JM, Schlievert PM (2003) Quorum sensing in Staphylococcus infections. J Clin Invest 112(11): 1620-1625 